Assessment of post-competition peak blood lactate in male and female master swimmers aged 40-79 years and its relationship with swimming performance

Piero Benelli, Massimiliano Ditroilo, Roberta Forte, Giuseppe De Vito, Vilberto Stocchi

European J ournal of Applied Physiology, Volume 99, Number 6, April, 2007, pages: 685-693

http:// dx.doi.org/ 10.1007/ s00421-006-0334-2 


\title{
Assessment of post-competition peak blood lactate in male and female master swimmers aged 40- 79 years and its relationship with swimming performance
}

\author{
Piero Benelli, Massimiliano Ditroilo, Roberta Forte, \\ Giuseppe De Vito, Vilberto Stocchi
}

\begin{abstract}
The main purpose of this study was to measure the postcompetition blood lactate concentration $\left([L a]_{b}\right)$ in master swimmers of both sexes aged between 40 and 79 years in order to relate it to age and swimming performance. One hundred and eight swimmers participating in the World Master Championships were assessed for [La $]_{b}$ and the average rate of lactate accumulation ( $\mathrm{La}^{\prime} ; \mathrm{mmol} \mathrm{I}^{-1} \mathrm{~s}^{-1}$ ) was calculated. In addition, 77 of them were also tested for anthropometric measures. When the subjects were divided into 10-year age groups, males exhibited higher [La $]_{b}$ than women (factorial ANOVA, $\mathrm{P}<0.01$ ) and a steeper decline with ageing than female subjects. Overall, mean values (SD) of $[\mathrm{La}]_{b}$ were $10.8(2.8), 10.3$ (2.0), $10.3(1.9), 8.9(3.2) \mathrm{mmol} \mathrm{I}^{-1}$ in women, and 14.2 (2.5), 12.4 (2.5), $11.0(1.6), 8.2(2.0) \mathrm{mmol} \mathrm{I}^{-1}$ in men for, respectively, 40-49, 50-59, 60-69, 70-79 years' age groups. When, however, [La $]_{b}$ values were normalised for a "speed index", which takes into account swimming speed as a percentage of world record, these sex-related differences, although still present, were considerably attenuated. Furthermore, the differences in La' between males and females were larger in the 40-49 age group $\left(0.34 \mathrm{vs} 0.20 \mathrm{mmol} \mathrm{I}^{-1} \mathrm{~s}^{-1}\right.$ for $50-\mathrm{m}$ distance) than in the 70-79 age group (0.12 vs $0.14 \mathrm{mmol} \mathrm{I}^{-1} \mathrm{~s}^{-1}$ for 50-m distance). Different physiological factors, supported by the considered anthropometric measurements, are suggested to explain the results.
\end{abstract}

Keywords Post-competition lactate, Ageing , Swimming, Master athletes

\section{Introduction}

In elderly subjects the evaluation of the primary effects of ageing on physiological functions is made particularly difficult by the confounding effects of the reduction in the level of habitual physical activity and by the possible concomitant occurrence of disease. The physiological assessment of master athletes is often suggested as a possible solution to exclude at least the factor of inactivity and gain a better understanding of the ageing process (Donato et al. 2003; Hawkins et al. 2003; Tanaka and Seals 1997).

The measurements of blood lactate concentration ([La $]_{b}$ ) following competition or maximal and sub-maximal exercise have been used, at least in young subjects, to assess exercise intensity and prescribe training (Bonifazi et al. 2000), to predict and optimise performance (Hautier et al. 1994) and, being aware of the limitations and provided that certain precautions are taken, to quantify the contribution of the anaerobic 
metabolism to the effort (e.g. di Prampero and Ferretti 1999; Lacour et al. 1990; Smith et al. 2002).

The research on [La $]_{b}$ following and during exercise in elderly individuals indicates, in general, that both lactate production and removal are reduced with respect to younger counterparts (Foster et al. 1986; Izquierdo et al. 2001).

Ageing causes modifications in body composition that alter the muscle structure and reduce the ability to perform exercises requiring strength and power (Macaluso and De Vito 2004). Fat and connective tissue infiltrates the muscle and the muscle fibre composition changes with a decrease in the number of both type I and II fibres, coupled with the selective atrophy of type II fibres (Macaluso and De Vito 2004; Taylor et al. 2004; Vandervoort 2002). All these factors may have a role in the altered production and removal of lactate observed in the elderly.

In master athletes the available literature on $[\mathrm{La}]_{\mathrm{b}}$ is varied and includes laboratory-based evaluations either following maximal exercise or following ad hoc exercise in the field (Reabourn and Mackinnon 1990). These studies, however, are difficult to compare due to the different methodologies followed, the exercises used (i.e. running, cycling or swimming), or the age of the master athletes involved.

In swimming, most of the published data on post-competition or postmaximal effort $[\mathrm{La}]_{\mathrm{b}}$ are relative to young or adult athletes and have been collected during the most favourable competition period (Avlonitou 1996; Bonifazi et al. 1993 and 2000; Chatard et al. 1988; McMaster et al. 1989; Ribeiro et al. 1990; Sawka et al. 1979). By contrast studies on master swimmers are scarce and limited either for the small number of subjects involved (Reaburn and Mackinnon 1990), or for the aspects of performance investigated (i.e. swimming times: Donato et al. 2003; Tanaka and Seals 1997). In addition, the information regarding the differences between sexes in master athletes is insufficient (Donato et al. 2003) although this may represent an important topic of investigation considering that, compared to men, older women have a reduced capacity for strength and power generation and therefore a potential decrease in the ability to perform specific daily tasks (Macaluso and De Vito 2004; Skelton et al. 1994). The measurement of post-competition $[\mathrm{La}]_{\mathrm{b}}$ in the master athletes of both genders could be a useful tool to further investigate the effects of ageing on muscle metabolism, especially when taking into consideration also the greater loss of muscular capacity and function present in women with respect to men. Only recently a study compared the post-competition [La] $]_{b}$ levels in master track and field athletes aged 40-88 (men) and 35-87 (women) reporting no differences between genders concerning the age-related decline in this parameter (Korhonen et al. 2005).

Hence, the aim of the present study was to assess, in male and female master swimmers aged between 40 and 79 years, the post-competition [ $\mathrm{La}]_{\mathrm{b}}$, in order to correlate it to age, gender and swimming performance.

It was hypothesised that $[\mathrm{La}]_{\mathrm{b}}$ would have shown a decline with age with 
women demonstrating lower values than men.

\section{Methods}

Subjects

The subjects were recruited from the athletes participating in the 10th Fina World Master Championships, held in Riccione (Italy) in J une 2004.

One hundred and eight athletes (females $=56$; males $=52$ ) distributed over the range 40-79 years were recruited by paper advertisement circulated before and during the championships venue. The means and SD according to the age categories for age, body mass, stature, fat-free mass (FFM), percentage of body fat ( $\% \mathrm{BF})$, thigh and forearm volumes (TV, FAV) are shown in Table 1 for both genders.

Subjects gave their written informed consent to participate in the study which was previously approved by the Human Ethics Committee of the University of Urbino (Italy). As shown in Table 1, however, not all participants underwent the complete set of measures. Of the 108 who were tested for the post-competition [La $]_{b}$, in fact, 29 (12 females and 17 males) did not agree to return for the remaining tests.

All measurements were held in three field laboratories organised in proximity of the race venue.

Table 2 shows the average speed achieved during the race and the final time achieved by the swimmers expressed as a percentage of the world record in each age group and swimming distance $(50,100,200,400)$, in males and females, divided into the following four 10-year age groups: 4049 (A), 50-59 (B), 60-69 (C), 70-79 (D). Most of the performances were, on average, between 15 and $35 \%$ worse than the respective world records. Three subjects set a new world record.

\section{Anthropometric measurements}

All the anthropometric measures were obtained with the subjects in the fasted state. Stature and body mass were measured with a telescopic rod and medical scales (Seca, Italy), respectively. For the calculation of the \% BF, skinfold thicknesses were measured using a 
Table 1 Age and physical characteristics of participants for both genders in each age category (mean \pm SD)

\begin{tabular}{llllllllll}
\hline $\begin{array}{l}\text { Age (years) } \\
\text { group }\end{array}$ & $n$ & Age (years) & $n$ & b. Mass (kg) & Stature (m) & FFM (kg) & b. Fat (\%) & FAV (l) & TV (l) \\
\hline Males & & & & & & & & \\
$40-49$ & 19 & $44.2 \pm 2.5$ & 10 & $81.2 \pm 9.9$ & $1.79 \pm 0.06$ & $63.9 \pm 5.5$ & $20.9 \pm 4.9 \dagger$ & $1.413 \pm 0.214$ & $4.593 \pm 0.612$ a \\
$50-59$ & 16 & $54.6 \pm 3.2$ & 9 & $84.2 \pm 9.9$ & $1.78 \pm 0.09$ & $61.9 \pm 4.4$ & $26.0 \pm 4.5$ & $1.409 \pm 0.159$ & $4.202 \pm 0.558$ \\
$60-69$ & 8 & $64.8 \pm 3.1$ & 6 & $80.8 \pm 10.2$ & $1.74 \pm 0.09$ & $58.9 \pm 6.2$ & $26.8 \pm 4.9$ & $1.247 \pm 0.141$ & $3.342 \pm 0.254 \mathrm{~b}$ \\
$70-79$ & 9 & $73.0 \pm 2.5$ & 8 & $81.1 \pm 7.6$ & $1.73 \pm 0.07$ & $58.6 \pm 5.3$ & $27.6 \pm 4.0 \dagger$ & $1.273 \pm 0.136$ & $3.491 \pm 0.870 \mathrm{c}$ \\
Total & 52 & & 33 & & & & & & \\
Females & & & & & & & & \\
$40-49$ & 19 & $44.1 \pm 3.6$ & 12 & $60.9 \pm 8.7$ & $1.65 \pm 0.07$ & $41.7 \pm 4.9$ & $31.3 \pm 3.8$ & $0.883 \pm 0.116$ & $3.013 \pm 0.486$ \\
$50-59$ & 17 & $53.9 \pm 2.7$ & 14 & $62.9 \pm 7.2$ & $1.64 \pm 0.05$ & $42.2 \pm 4.3$ & $32.6 \pm 4.2$ & $0.926 \pm 0.133$ & $3.082 \pm 0.595$ \\
$60-69$ & 11 & $64.6 \pm 3.0$ & 11 & $59.6 \pm 6.2$ & $1.62 \pm 0.05$ & $40.2 \pm 2.5$ & $32.2 \pm 5.0$ & $0.893 \pm 0.107$ & $3.013 \pm 0.468$ \\
$70-79$ & 9 & $73.1 \pm 2.6$ & 7 & $63.6 \pm 12.8$ & $1.63 \pm 0.08$ & $41.8 \pm 5.5$ & $33.4 \pm 5.8$ & $0.918 \pm 0.115$ & $2.983 \pm 0.786$ \\
Total & 56 & & 44 & & & & & & \\
\hline
\end{tabular}

FFM fat-free mass; $F A V$ muscle-bone forearm volume; $T V$ muscle-bone thigh volume

$\dagger$ Significantly different from each other $(P<0.05)$; a is significantly different from $\mathrm{b}$ and $\mathrm{c}(P<0.01)$

Table 2 Average speed $\left(\mathrm{m} \mathrm{s}^{-1}\right)$ and swimming performance time expressed as a percentage of the world record (WR perf.) according to swimming distance and age group, in males and females

\begin{tabular}{|c|c|c|c|c|c|c|c|c|c|c|c|c|}
\hline & \multicolumn{3}{|l|}{50} & \multicolumn{3}{|c|}{100} & \multicolumn{3}{|c|}{200} & \multicolumn{3}{|c|}{400} \\
\hline & $n$ & Speed & $\%$ WR perf. & $n$ & Speed & $\%$ WR perf. & $n$ & Speed & $\%$ WR perf. & $n$ & Speed & $\%$ WR perf. \\
\hline \multicolumn{13}{|c|}{ Males } \\
\hline A & 4 & $1.47(0.22)$ & $126.0(8.3)$ & 9 & $1.53(0.22)$ & $114.8(7.9)$ & 3 & $1.39(0.04)$ & $106.2(2.7)$ & 3 & $1.24(0.08)$ & $116.0(17.4)$ \\
\hline B & 2 & $1.40(0.05)$ & $120.1(9.5)$ & 8 & $1.32(0.20)$ & $117.4(6.8)$ & 5 & $1.09(0.23)$ & $123.9(20.0)$ & 1 & 1.23 & 125.0 \\
\hline $\mathrm{C}$ & 0 & & & 2 & $1.33(0.27)$ & $111.0(2.4)$ & 4 & $1.01(0.27)$ & $118.3(17.9)$ & 1 & 0.76 & 150.0 \\
\hline D & 2 & $1.03(0.09)$ & $143.5(5.1)$ & 0 & & & 3 & $0.77(0.04)$ & $146.1(30.8)$ & 1 & 0.91 & 141.0 \\
\hline All & 8 & $1.34(0.25)$ & $128.9(11.6)$ & 19 & $1.42(0.23)$ & $115.5(7.1)$ & 15 & $1.07(0.27)$ & $123.3(22.4)$ & 6 & $1.11(0.22)$ & $127.4(18.4)$ \\
\hline \multicolumn{13}{|c|}{ Females } \\
\hline A & 2 & $1.30(0.25)$ & $126.6(8.3)$ & 5 & $1.05(0.09)$ & $132.2(9.6)$ & 7 & $1.06(0.11)$ & $124.6(13.3)$ & 4 & $1.06(0.01)$ & $125.5(18.0)$ \\
\hline B & 0 & & & 5 & $0.99(0.06)$ & $122.4(13.2)$ & 5 & $1.00(0.23)$ & $132.0(27.7)$ & 7 & $0.96(0.19)$ & $133.5(21.9)$ \\
\hline $\mathrm{C}$ & 1 & 1.15 & 137.7 & 6 & $1.02(0.19)$ & $118.9(11.9)$ & 4 & $0.80(0.07)$ & $124.0(10.6)$ & 0 & & \\
\hline $\mathrm{D}$ & 1 & 0.93 & 126.8 & 3 & $0.84(0.18)$ & $133.1(15.0)$ & 3 & $0.85(0.08)$ & $131.1(22.8)$ & 1 & 0.86 & 127.0 \\
\hline All & 4 & $1.17(0.23)$ & $129.3(7.2)$ & 19 & $0.09(0.15)$ & $125.6(12.8)$ & 19 & $0.96(0.17)$ & $127.4(17.9)$ & 12 & $0.99(0.15)$ & $130.3(19.1)$ \\
\hline
\end{tabular}

Harpenden skinfold calliper (British Indicators LTD, West Sussex, UK) at four sites: biceps, triceps, subscapular, and suprailiac. Measures were taken at the dominant side, with the subject standing relaxed with the legs slightly apart. Three measures were taken at each site and the average was used for statistical computations. Body density (BD), \%BF and FFM were later calculated according to Durnin and Womersley (1974).

Thigh volume and FAV were estimated adopting a modified version of the anthropometric method proposed by Jones and Pearson (1969). Briefly, the length from the gluteal furrow to the minimum circumference above the knee and the circumferences at three sites were taken with a fibreglass measuring tape, on the dominant leg of standing subject. The circumference sites were as follows: the gluteal furrow, one-third of the subischial height up from the tibial-femoral joint space and the minimum circumference above the knee. Skinfold measurements were then taken at two sites: anterior and posterior mid thigh using a Harpended skinfold calliper. Skinfold corrections for fat were made using the following regression equations (Professor P.R.M. Pearson, personal communication): anterior thigh $(\mathrm{y}=1.01419+0.55696$ skinfold value) and posterior thigh ( $y=1.36874+0.53231$ skinfold value), where y represents the corrected skinfold value used in the calculations. The formula to calculate the volume (V) of a truncated cone was applied to the 
two truncated cones:

$$
V=1 / 3 h(a+\sqrt{(a b)}+b),
$$

where $a$ and $b$ are the areas of two parallel surfaces derived from the abovementioned measurements and $h$ is the vertical distance between them. Finally, the muscle bone volume was calculated including the two corrected skinfold readings.

For the FAV calculation, the same assumptions were made as for the TV. The subject stood with the dominant arm extended in the horizontal plane. The circumferences at three sites and the lengths at two sites were taken with a fibreglass measuring tape: the elbow girth, at the olecran process at the ulna level, the maximum forearm girth (usually within $5 \mathrm{~cm}$ from the elbow) and the wrist girth; the length from wrist to the maximum forearm girth and from wrist to the olecran process of ulna. Furthermore, the vertical skinfold thickness taken at the level of maximum forearm girth on the lateral aspect of the forearm was measured, using a Harpenden skinfold calliper.

\section{Lactate measurement}

Blood samples were collected $5 \mathrm{~min}$ after the end of the selected race. A member of the research team waited for the athlete at the side of the pool and was responsible for checking the time for sample collection and for guiding the athlete to the laboratory situated $50 \mathrm{~m}$ from the swimming pool. At the completion of the 5th minute of recovery, a capillary blood sample was taken from the fingertip. [ $\mathrm{La}]_{\mathrm{b}}\left(\mathrm{mmol} \mathrm{I}^{-1}\right)$ was immediately analysed by a portable lactate analyser (Lactate Pro, Arkray Inc., Kyoto, Japan) previously validated (Pyne et al. 2000).

\section{Average speed}

The performance of swimmers, expressed as average speed achieved during competition, was calculated simply by dividing the distance covered by the final time taken from the printed output of the pool's automatic timing device.

\section{Statistical analysis}

Data were analysed for normality of distribution by calculating kurtosis and skewness of the data. Firstly, in order to analyse the age and gender effect on post-competition [ $\mathrm{La}]_{b}$, subjects were divided into 10-year age groups and analysed adopting a two-way factorial ANOVA (gender and age-group) and also considering the performance time (t), expressed in seconds, as a covariate. Moreover, an additional factorial ANOVA (gender and age group) was adopted using [ $\mathrm{La}]_{\mathrm{b}}$ values normalised for a "speed index", in order to take into account not only the different durations but also the level of intensity of the swims. In the present study, average swimming speed and 
[La] $]_{b}$ were positively and linearly related $(r=0.49$ and $r=0.52$ in females and males, respectively; $P<0.01$ ) although the correlation coefficient is moderate. The speed index was calculated by dividing each [ $\mathrm{La}]_{\mathrm{b}}$ value by the reciprocal of the performance time (in percentage of the world record). When a significant main or interaction effect was found, a Tukey HSD post hoc test was used to locate the differences. The net lactate accumulation (NLA) was also calculated simply by subtracting from [La $]_{\mathrm{b}} 1 \mathrm{mmol} \mathrm{I}^{-1}$, which can be conveniently considered the lactate resting value. Then the average rate of lactate accumulation (La' ) was obtained dividing NLA by $t(s)$ and expressed as: $\mathrm{mmol} \mathrm{I}^{-1} \mathrm{~s}^{-1}$. $\mathrm{La}^{\prime}$ and $\mathrm{t}$, calculated and measured for the four distances considered, were then scatter-plotted, taking into account the agegroups and the gender. The points fitted a first-order hyperbolic equation: $\mathrm{La}^{\prime}=\mathrm{K}+(\mathrm{a} / \mathrm{t})$. Owing to a lack of data, especially those concerning the $50-\mathrm{m}$ and $400 \mathrm{~m}$ distance, the plots and regression equations were performed only in groups $A$ and $D$.

Simple ANOVA was used to compare FAV, TV, \%BF across the four groups considered, in males and females, followed by a Tukey HSD when a significant difference was found.

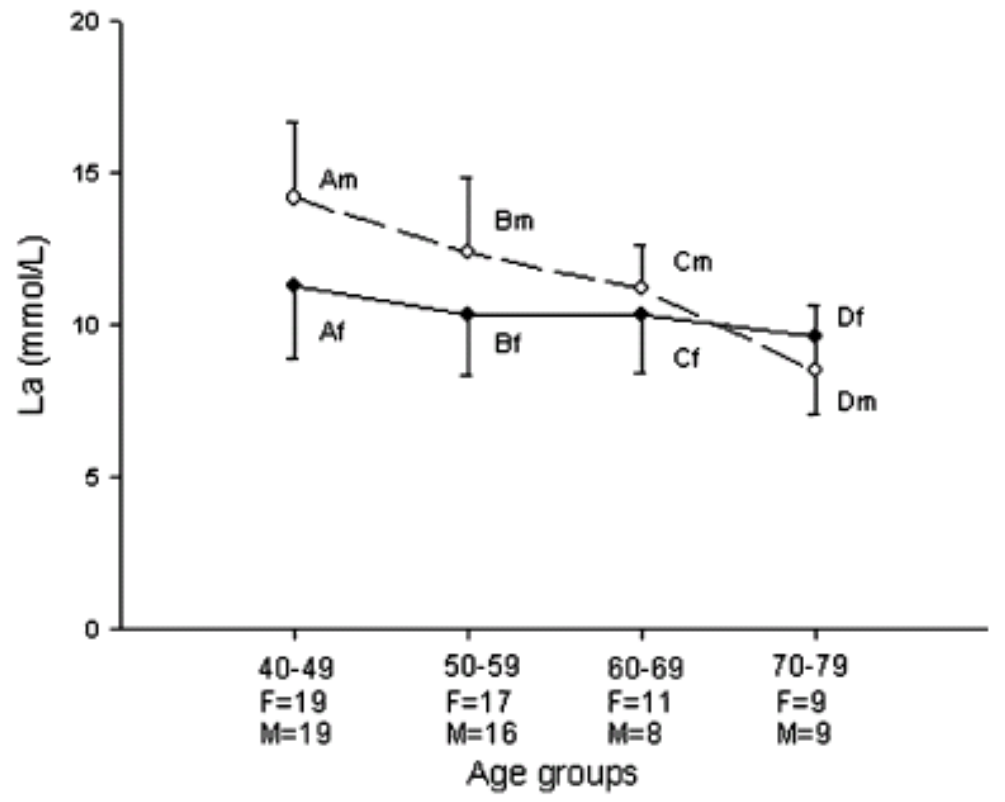

Fig. 1 Post-competition $[\mathrm{La}]_{b}$ values (means $\pm \mathrm{SD}$ ) measured in the four age groups. Males' results are indicated by the white dots and the dotted line. Females' results are indicated by the black dots and the closed line. Beside each dot are reported the age group (A, B, C, D) and the corresponding gender $(\mathrm{m}, \mathrm{f})$. Statistics (Tukey post hoc): $A m>C m^{*}, D m^{* *}, A f^{* *}, B f^{* *}, C f^{* *}$, $D f^{* *} B m>D m^{* *}, D f^{*}$, where $*=P<0.05$ and $* *=P<0.01$ 
Results

Figure 1 shows for both genders the post-competition [La] $]_{b}$ results for the four considered groups. Significant main effects were observed for both gender $(P<0.01)$ and age-group $(P<0.01)$ factors, with males exhibiting higher values than women. In addition, no significant effect of the covariate $t$ was demonstrated. It is of interest to note that in females no differences in [La]b were observed across the 40 to 79 years' groups. By contrast, male athletes exhibited a significant age-re-lated decline. The post hoc analysis (Tukey) revealed differences between $A$ and $C(P<0.05)$ and $A$ and $D$ male groups $(P<0.01)$. In addition, $A$ male group $[\mathrm{La}]_{b}$ values were higher than all the four females groups $(P<0.01)$, whereas $B$ male group values were also higher than $D$ male $(P<0.05)$ and female groups $(P<0.01)$.

On the other hand, when the $[\mathrm{La}]_{b}$ values were normalised using the "speed index" (Fig. 2), although a main effect of gender and age group factors was still evident, the differences were considerably reduced. The post hoc analysis revealed, in males, significant differences only between group $A$ and group $D(P<0.05)$. Besides, gender differences were revealed only between male group $A$ and female group $B(P<0.05), C(P<0.01)$ and $D(P$ $<0.05)$.

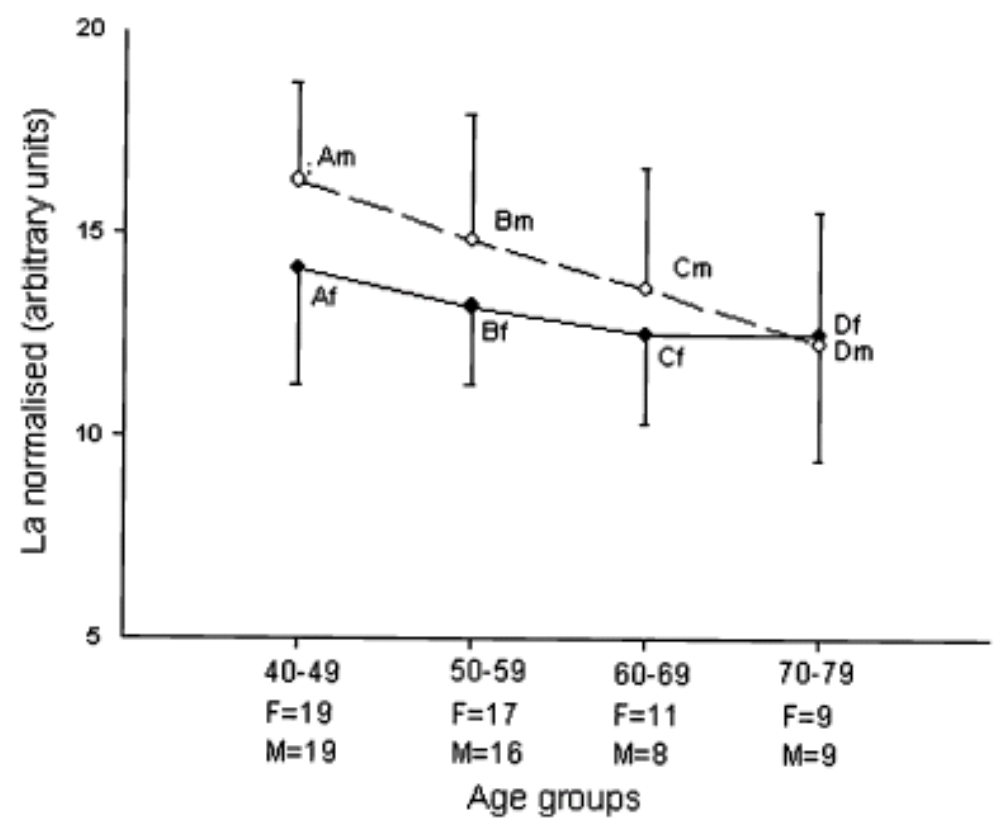

Fig. 2 Post-competition $[\mathrm{La}]_{b}$ values (means $\pm \mathrm{SD}$ ), normalised for a "speed index" (see Methods for details), measured in the four age groups. Males' results are indicated by the white dots and the dotted line. Females' results are indicated by the black dots and the closed line. Beside each dot are reported the age group $(\mathrm{A}, \mathrm{B}, \mathrm{C}, \mathrm{D})$ and the corresponding gender $(\mathrm{m}, \mathrm{f})$. Statistics (Tukey post hoc): $A m>D m^{*}, B f^{*}, C f^{* *}, D f^{*}$ where $*=P<0.05$ and $* *=P<0.01$ 
Table 3 shows, for both genders, divided into age groups, the different distances in which the swimmers competed and the average [La] $]_{b}$ values measured. The highest [La] $]_{b}$ values were found in 100 and $200 \mathrm{~m}$, whilst the individual peak values were $17.3 \mathrm{mmol} \mathrm{l}^{-1}$ in $100-\mathrm{m}$ freestyle men (in a swimmer of 47 years of age) and $15.8 \mathrm{mmol} \mathrm{I}^{-1}$ in $200-\mathrm{m}$ butterfly women (in a swimmer of 49 years of age).

Figure 3 put into relation the La' versus $t$ for groups $A$ and $D$, comparing males and females. The amount of energy per unit of body mass $\left(\mathrm{ml} \mathrm{O}_{2} \mathrm{~kg}^{-1}\right.$ $\min ^{-1}$ ), obtained multiplying NLA by $3.3 \mathrm{ml} \mathrm{O}_{2} \mathrm{~kg}^{-1} \mathrm{mmol} \mathrm{l}^{-1}$, is also reported on the right ordinate of the plot (Di Prampero and Ferretti 1999).

Although a statistical analysis was not performed, a visual inspection of the plots, with the support of the regression equations, allows to provide some indications. La' for $50-\mathrm{m}$ distance decreased moving from group $A$ to $D$, especially in males and not surprisingly the same trend is evident for the $V$ $\mathrm{O}_{2}$ eq results. The constant " $\mathrm{K}$ " in the equations represents La' when t tends to infinity. This is quite similar in the four groups ( $A$, males and females; $D$, males and females). Constant " $a$ ", on the other hand, is related to the horizontal displacement of the curve. An increase in "a" makes the curve slightly moving towards the right which means an increase in La' when the $t$ is low, or rather when the average speed is high. When considering group $A$, in males "a" (11.6) was more than 1.5 times higher than in females (7.6). On the other hand, in group $D$ the gender-related difference was much more attenuated ( 5.5 vs 6.9). When the rate of "a" reduction, from group A to $D$, was analysed, it resulted to be $52.8 \%$ in men (from 11.6 to 5.5 ) and $9.6 \%$ in women (from 7.6 to 6.9).

\section{Discussion}

The main purpose of this study was to measure post-competition [La]b in master swimmers aged between 40 and 79 years in order to relate it to age, gender and swimming performance. To the best of our knowledge, this is the first time that data on [La $]_{b}$ post-competi-tion, collected from a large group of master swimmers, are presented. This study, however, presents some limitations that must be underlined.

Firstly, the subjects volunteered for participating in the study and the individual performance level was not an inclusion criteria. On the other hand to participate in the competition they had to reach the world championships time entry. Indeed, in most age groups and events, the average swimming performance was between 15 and 35\% higher than the world record, with women performing slightly worse than men. 
Table 3 Average lactate values (SD) measured $5 \mathrm{~min}$ after the race according to swimming distance and age group, in males and females

\begin{tabular}{|c|c|c|c|c|c|c|c|c|}
\hline & \multicolumn{2}{|l|}{50} & \multicolumn{2}{|c|}{100} & \multicolumn{2}{|c|}{200} & \multicolumn{2}{|c|}{400} \\
\hline & $n$ & Lactate $\left(\mathrm{mmol} \mathrm{l}^{-1}\right)$ & $n$ & Lactate $\left(\mathrm{mmol} \mathrm{l}^{-1}\right)$ & $n$ & Lactate $\left(\mathrm{mmol} \mathrm{l}^{-1}\right)$ & $n$ & Lactate $\left(\mathrm{mmol} \mathrm{l}^{-1}\right)$ \\
\hline \multicolumn{9}{|c|}{ Males } \\
\hline A & 4 & $12.6(1.8)$ & 9 & $15.4(1.5)$ & 3 & $15.9(1.0)$ & 3 & $11.2(3.5)$ \\
\hline B & 2 & $10.7(1.6)$ & 8 & $12.3(3.0)$ & 5 & $13.5(2.0)$ & 1 & 11.2 \\
\hline $\mathrm{C}$ & 1 & 8.9 & 2 & $10.2(2.0)$ & 4 & $11.8(1.4)$ & 1 & 11.1 \\
\hline D & 4 & $6.7(1.1)$ & 0 & & 3 & $8.4(0.2)$ & 2 & $10.8(2.2)$ \\
\hline All & 11 & $9.8(3.0)$ & 19 & $13.5(2.9)$ & 15 & $12.5(2.9)$ & 7 & $11.1(2.2)$ \\
\hline \multicolumn{9}{|c|}{ Females } \\
\hline A & 3 & $7.4(2.7)$ & 5 & $10.5(2.5)$ & 7 & $12.6(2.3)$ & 4 & $10.9(1.8)$ \\
\hline B & 0 & & 5 & $10.0(2.4)$ & 5 & $11.7(2.0)$ & 7 & $9.6(1.5)$ \\
\hline C & 1 & 12.2 & 6 & $11.0(1.4)$ & 4 & $8.8(1.8)$ & 0 & \\
\hline D & 1 & 8.3 & 4 & $7.6(3.6)$ & 3 & $10.9(3.1)$ & 1 & 9.1 \\
\hline All & 5 & $8.5(2.8)$ & 20 & $9.9(2.6)$ & 19 & $11.3(2.5)$ & 12 & $10.0(1.6)$ \\
\hline
\end{tabular}

In order to simplify the table the data are presented just for distance and not for stroke

$\mathrm{A}=40-49$ age group; $\mathrm{B}=50-59$ age group; $\mathrm{C}=60-69$ age group; $\mathrm{D}=70-79$ age group

Fig. 3 Average rate of lactate accumulation ( $\left.\mathrm{La}^{\prime}\right)$

calculated for the 50-, 100-,

200- and 400-m swimming

distances, related to the

performance time. Every

point in the plot was obtained

by averaging the net lactate

accumulation $(N L A)$ and the

performance time, taking into account swimming distance,

gender and age group $\mathrm{A}$ and

D. On the right ordinate of

the plot is also reported the

amount of energy per unit of

body mass $\left(\mathrm{ml} \mathrm{O}_{2} \mathrm{~kg}^{-1} \mathrm{~min}^{-1}\right)$

generated by the

accumulation of $1 \mathrm{mmol} \mathrm{l}^{-1}$ of

lactate in blood. A hyperbolic

regression equation is also

shown

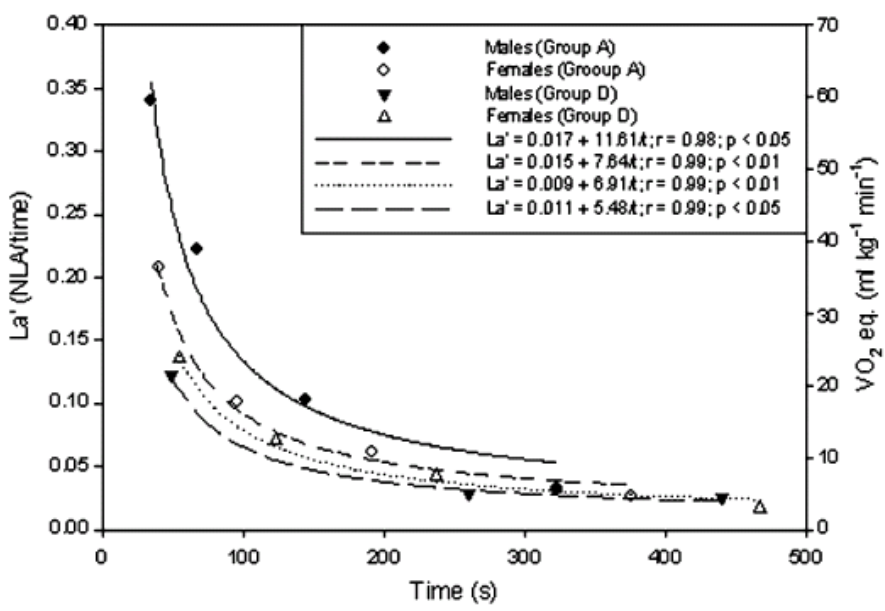

Secondly, subjects took part in quite different events varying in distance (ranging from 50 to $400 \mathrm{~m}$ ) and stroke (freestyle, butterfly, breaststroke, backstroke, medley), hence encompassing different metabolic requirements. We tried to minimise these last two problems by considering not only the absolute post competition [ $\mathrm{La}]_{\mathrm{b}}$ values but also the $[\mathrm{La}]_{\mathrm{b}}$ normalised adopting a "speed index".

Thirdly, the level of maximal post-competition [La] $]_{b}$ was obtained with only one blood sample collected $5 \mathrm{~min}$ after the end of the race. Although this procedure was used previously (e.g. Bonifazi et al. 1993; Sawka et al. 1979), a lactate kinetics would have been more accurate for determining the peak of $[\mathrm{La}]_{\mathrm{b}}$.

These limitations were, however, unavoidable since the study had to be conducted, during the championships, in a field laboratory at the side of the swimming pool to maximise subject's recruitment. It has been previously reported that the highest values of $[\mathrm{La}]_{\mathrm{b}}$ are not obtained in training or during ad hoc organised testing, but following important competitions (Bonifazi et al. 2000; Sawka et al. 1979). For this purpose the present study was carried out during the world championships in the attempt to possibly ensure the best motivation and effort by the subjects. 
Both absolute and normalised results of post-com-petition [La] $]_{b}$ showed no significant effects of advancing age in females ranging from 40 to 79 years of age. On the other hand, a significant decline was evident in men (Fig. 1) even when the values were normalised (Fig. 2). This is in contrast to a previous study by Reaburn and Mackinnon (1990) who did not observe a similar trend in male master swimmers, although their data are not easily comparable to ours since they were based on younger master athletes and on a small number of subjects. In addition, the ANOVA showed a significant main effect for gender with men having higher [ $\mathrm{La}]_{b}$ values then women. This trend is also confirmed by the analysis of La' related to t. The La' for $50 \mathrm{~m}$ distance was larger in men of group A com-pared to women $(0.34$ vs 0.20 $\mathrm{mmol} \mathrm{I}^{-1} \mathrm{~s}^{-1}$ ). Instead, the difference between males and females of group $D$ was considerably attenuated $\left(0.12 \mathrm{vs} 0.14 \mathrm{mmol} \mathrm{I}^{-1} \mathrm{~s}^{-1}\right)$. Overall, it could be said that the most important difference in La' between younger and older age groups was concentrated in the first $100 \mathrm{~s}$ of competition and this was particularly evident in males. When $t$ becomes higher than, approximately, $300 \mathrm{~s}$, the differences among the groups tended to disappear.

This distinct age-related trend in post-competition [La $]_{b}$ and La' between males and females could be due to a number of factors. It is well known that postexercise lactate concentration depends on both the total muscle mass engaged in the activity (Jensen-Urstad et al. 1994) and the total individual plasma volume (Berthoin et al. 2002). Men have a greater skeletal muscle mass than women, and it has been demonstrated that the rate of age-related decrease of relative skeletal muscle mass (normalised to body mass) is greater in men compared to women (Janssen et al. 2000). Ageing is associated with a decrease in total plasma volume; however, it has been demonstrated that total blood, plasma, and erythrocyte cell volumes are well maintained in older physically active females (Jones et al. 1997). Therefore, it could be speculated that, in the present study, the [ $\mathrm{La}]_{\mathrm{b}}$ decline with age, which was apparent only in men, could be due mainly to the greater loss in muscle skeletal mass experienced by males compared to female athletes. This is also supported by the measurements of FAV, TV and \%BF used in the present study. Although the differences in FAV across the groups, both in males and females, are not significant, males exhibited a significant reduction in TV and a significant increase in \% BF.

The age-related decrease in whole muscle mass reflects a loss in the number of fibres occurring equally for fast-and slow-twitch fibres and a reduction in the cross-sectional area of the single fibres, particularly evident in the fast-twitch ones (Deschenes 2004; Kir-kendall and Garrett 1998). Since the glycolytic metabolism depends on muscle mass, especially on the proportion of fast-twitch fibres, muscles with the same area, but occupied by a relatively smaller area of fast-twitch fibres, will be able to generate less $[\mathrm{La}]_{b}$ and lower La'. Ageing seems to affect minimally the efficiency of the glycolytic enzymes (Kirkendall and Garrett 1998); however, it has been previously shown that in young adults the maximal activity of glycolytic enzymes is higher in males than in females with the latter showing a reduced capacity for anaerobic glycolysis (Green et al. 1984). 
Another potential reason to explain the distinct age-related trend in postexercise $[\mathrm{La}]_{\mathrm{b}}$ observed in male compared to female athletes could be linked to differences in the rate of decline in the levels of many hormones. Women live most of their life in the hypoestrogenic state and indeed most of the female athletes who participated in the present study were postmenopausal. This condition is associated to a number of negative alterations affecting different organ and systems such as osteoporosis, muscle weakness and poor cardiovascular performance (Rehman and Mas-son 2005). On the other hand, in men, with ageing, the hormonal alterations occur more slowly and subtly than the corresponding alterations in women. It has been demonstrated a reduced acute hormonal response (total and free testosterone, GH) to heavy resistance isometric exercise, together with lowered basal values in free testosterone in older men compared to younger ones ( $\mathrm{Ha}$ " kkinen et al. 1998; Izquierdo et al. 2001). It could be therefore the case that the men in group A (40-49 years) were still exhibiting normal or near normal hormonal levels and that this potential hormonal effect was evident only in the older male groups.

Peaks of $[\mathrm{La}]_{\mathrm{b}}$ were observed in distances ranging from 100 to $200 \mathrm{~m}$. This is even consistent with the results of studies conducted on young competitive swimmers (Avlonitou 1996; Bonifazi et al. 1993; Chatard et al. 1988; Sawka et al. 1979). In line with these findings is also the positive correlation found between [La $]_{b}$ and average speed achieved in the races, both in males and females. It is also important to add that the [La $]_{b}$ values obtained from the present athletes are comparable to those measured in younger subjects for the same race/distance (Avlonitou 1996; Bonifazi et al. 1993; Sawka et al. 1979), in contrast to the general belief that in elderly lactate production is reduced (Foster et al. 1986; Izquierdo et al. 2001; among the others).

In conclusion, it can be said that, post-competition [La]b levels were significantly higher and showed a steeper age-related decline in men compared to women, even when the values were adjusted by $t$. Peaks of $[\mathrm{La}]_{\mathrm{b}}$ were not significantly different from those measured in younger swimmers for the same race-dis-tances. Furthermore, La' was higher in younger male swimmers compared to females, but the difference was considerably reduced in older age groups.

The results of the present study, due to the above-mentioned limitations cannot be easily generalised to the entire population. Therefore, further investigations are necessary for a better understanding of the real differences between ageing males and female athletes in post-competition $[\mathrm{La}]_{\mathrm{b}}$.

Acknowledgments The authors are grateful to C. Castagna, C. Santini, M. Del Sal, E. Ferna'ndez Peña, A. Freddo, D. Gambarara, E. Grassi, A. Ramadori and $\mathrm{M}$. Tiberi for their assistance and cooperation in collecting data. 


\section{References}

Avlonitou E (1996) Maximal lactate values following competitive performance varying according to age, sex and swimming style. J Sports Med Phys Fitness 36:24-30

Berthoin S, Pelayo P, Baquet G, Marais G, Allender H, Robin H (2002) Plasma lactate recovery from maximal exercise with correction for variations in plasma volume. J Sports Med Phys Fitness 42:26-30

Bonifazi M, Martelli G, Marugo L, Sardella F, Carli G (1993) Blood lactate accumulation in top level swimmers following competition. J Sports Med Phys Fitness 33: 13-18

Bonifazi M, Sardella F, Lupo C (2000) Preparatory versus main competitions: differences in performances, lactate responses and pre-competition plasma cortisol concentrations in elite male swimmers. Eur J Appl Physiol 82: 368-373

Chatard JC, Paulin M, Lacour JR (1988) Post competition blood lactate measurement and swimming performance. In: Ungerechts BE, Wilkie K, Reischle K (eds) Swimming science V. Human Kinetics Books, Champaign, pp 311-316

Deschenes MR (2004) Effects of aging on muscle fibre type and size. Sports Med 34:809-824

Di Prampero PE, Ferretti G (1999) The energetics of anaerobic muscle metabolism: a reappraisal of older and recent concepts. Respir Physiol 118: 103- 115

Donato AJ, Tench K, Glueck DH, Seals DR, Eskurza I, Tanaka H (2003) Declines in physiological functional capacity with age: a longitudinal study in peak swimming performance. J Appl Physiol 94:764-769

Durnin JV, Womersley J (1974) Body fat assessed from total body density and its estimation from skinfold thickness: measurements on 481 men and women aged from 16 to 72 years. Br J Nutr 32:77-97

Foster VL, Hume GJ, Dickinson AL, Chatfield SJ, Byrnes WC (1986) The reproducibility of $\mathrm{VO}_{2}$ max, ventilatory, and lactate thresholds in elderly women. Med Sci Sports Exerc 18:425-430

Green HJ, Fraser IG, Ranney DA (1984) Male and female differences in enzyme activities of energy metabolism in vastus lateralis muscle. J Neurol Sci 65: 323-331

Ha"kkinen K, Pakarinen A, Newton RU, Kraemer WJ (1998) Acute hormone responses to heavy resistance lower and upper extremity exercise in young versus old men. Eur J Appl Physiol Occup Physiol 77:312-319

Hautier CA, Wouassi D, Arsac LM, Bitanga E, Thiriet P, Lacour JR (1994) Relationships between postcompetition blood lactate concentration and average running velocity over $100 \mathrm{~m}$ and $200-\mathrm{m}$ races. Eur J Appl Physiol Occup Physiol 68:508-513

Hawkins SA, Wiswell RA, Marcell TJ (2003) Exercise and the master athlete-a model of successful aging? J Gerontol A Biol Sci Med Sci 58: 1009- 1011 
Izquierdo M, Hakkinen K, Anton A, Garrues M, Ibanez J, Ruesta $M$, Gorostiaga EM (2001) Maximal strength and power, endurance performance, and serum hormones in middle-aged and elderly men. Med Sci Sports Exerc 33: 1577-1587

Janssen I, Heymsfield SB, Wang ZM, Ross R (2000) Skeletal muscle mass and distribution in 468 men and women aged 18-88 yr. J Appl Physiol 89: $81-88$

Jensen-Urstad M, Svedenhag J, Sahlin K (1994) Effect of muscle mass on lactate formation during exercise in humans. Eur J Appl Physiol 69:189195

Jones PRM, Pearson J (1969) Anthropometric determination of leg fat and muscle plus bone volumes in young male and female adults, Proceedings of the Physiological Society. J Physiol 204:63-66

Jones PP, Davy KP, DeSouza CA, van Pelt RE, Seals DR (1997) Absence of age-related decline in total blood volume in physically active females. Am J Physiol 272: $\mathrm{H} 2534-\mathrm{H} 2540$

Kirkendall DT, Garrett WE Jr (1998) The effects of aging and training on skeletal muscle. Am J Sports Med 26:598-602

Korhonen MT, Suominen H, Mero A (2005) Age and sex differences in blood lactate response to sprint running in elite master athletes. Can J Appl Physiol 30: 647-665

Lacour JR, Bouvat E, Barthelemy JC (1990) Post-competition blood lactate concentrations as indicators of anaerobic energy expenditure during 400$\mathrm{m}$ and 800-m races. Eur J Appl Physiol Occup Physiol 61:172-176

Macaluso A, De Vito G (2004) Muscle strength, power and adaptations to resistance training in older people. Eur J Appl Physiol 91:450-472

McMaster WC, Stoddard T, Duncan W (1989) Enhancement of blood lactate clearance following maximal swimming. Effect of velocity of recovery swimming. Am J Sports Med 17:472- 477

Pyne DB, Boston T, Martin DT, Logan A (2000) Evaluation of the Lactate Pro blood lactate analyser. Eur J Appl Phys 82:112-116

Reaburn PRJ, Mackinnon LT (1990) Blood lactate responses in older swimmers during active and passive recovery following maximal sprint swimming. Eur J Appl Physiol 61:246- 250

Rehman HU, Masson EA (2005) Neuroendocrinology of female aging. Gend Med 2:41-56

Ribeiro JP, Cadavid E, Baena J, Monsalvete E, Barna A, De Rose EH (1990) Metabolic predictors of middle-distance swimming performance. $\mathrm{Br} J$ Sports Med 24: 196-200

Sawka MN, Knowlton RG, Miles DS, Critz JB (1979) Post-competition blood lactate concentrations in collegiate swimmers. Eur J Appl Physiol Occup Physiol 41:93-99

Skelton DA, Greig CA, Davies JM, Young A (1994) Power and related functional ability of healthy people aged 65- 89 years. Age Ageing 23: $371-377$

Smith DJ, Norris SR, Hogg JM (2002) Performance evaluation of swimmers. Sports Med 32:539-554

Tanaka H, Seals DR (1997) Age and gender interactions in physiological 
functional capacity: insight from swimming performance. J Appl Physiol 82: 846-851

Taylor AH, Cable NT, Faulkner G, Hillsdon M, Narici M, Van Der Bij AK (2004) Physical activity and older adults: a review of health benefits and the effectiveness of interventions. J Sport Sci 22:703-725

Vandervoort AA (2002) Aging of the human neuromuscular system. Muscle Nerve 25: 17- 25 